\title{
Software product to reduce commercial energy losses
}

\author{
Maksim Vladimirovich Borodin ${ }^{1, *}$, Tatyana Anatolievna Kudinova ${ }^{2}$, and Zumeyra Munirovna Shakurova ${ }^{3}$ \\ ${ }^{1}$ Orel State Agrarian University named after N.V. Parakhin, Orel, Russia \\ ${ }^{2}$ Orel State Agrarian University named after N.V. Parakhin, Orel, Russia \\ ${ }^{3}$ Kazan State Power Engineering University, Kazan, Russia
}

\begin{abstract}
The personnel of electric grid companies spend considerable amount of time searching for noncontractual and non-meteredelectricity consumption. The raids carried out by personnel of electric grid companies to detect electricity theft are not always effective, as they are carried out selectively and often do not take into account many factors that could affect the number of detected cases of electricity theft. The article proposes a software product that allows, on the basis ofconsumers' registration, who have already stolen electricity, have arrears in payment for consumed electricity, made uncontrolled consumption, carry out a process of technological connection or have non-meter accounting, to send personnel conducting a raid to identify electricity theft. It also makes possible to generate the necessary acts, certificates, etc.in real time, which allows staff to reduce the time to fill out paper versions and transfer the necessary documents to the police. The software product allows to increase the efficiency of raids by electric grid companies, by reducing the time of inspections. In turn, the implementation of the proposed software product will allow electric grid companies to significantly reduce energy losses by increasing the territoriality of raids.
\end{abstract}

\section{Introduction}

The authors $[1,9,14,15]$ indicate that, at present, in Russia, the imperfection of the regulatory framework in the field of electricity metering leads to non-meteredand non-contractual use of electricity, as well as legal disputes between the consumer and the power supply organization. The work carried out by the state and power supply companies in this direction is not sufficiently effective.

In order to reduce the number of non-metered and non-contractual energy consumption, it is necessary to improve the regulatory framework, make the necessary amendments and changes to it to implement tools aimed at reducing the number of non-metered and noncontractual electricity consumptionmore efficiently. Also, in order to reduce the number of non-metered and non-contractual electricity consumption, electricity grid companies themselves must use modern tools aimed at reducing electricity losses.

Literary sources $[2-8,10-13,16-20]$ indicate that a lot of time is spent by the electric grid company personnel on identifying electricity theft by consumers. Raids carried out by electric grid company personnel to detect electricity theft are not always effective, as they are carried out selectively and often the balance of consumption by feeder, settlement, etc. is not taken into account.

\section{Research methodology}

In the electric grid company ofPJSC "IDGC(Interregional Distribution Grid Company) of Center", the rules of procedure for WG BP 7 / 03-06 / 2018 "Work on the identification and exclusion of noncontractual, non-meteredelectricity consumption", regulating the algorithm for conducting raids by personnelare developed, but they are not entirely effective from our point of view.So, in clause 6.1 of the procedure rules of the WG BP 7 / 03-06 / 2018 "Work on the identification and exclusion of non-contractual, non-metered electricity consumption" it is indicated that SAP has the CIRMS (corporate information resource management system) functionality (SAP IS-U "Route sheet"). But the CIRMS functionality does not take into account non-meter consumers (that is, consumers who do not have a meter, but they pay according to the standard) and consumers found to be stealing electricity. It is necessary to take into account non-meterconsumers, since they can consume electricity above the established norm. At the same time, the personnel performing the raids do not have devices that can measure electricity consumption. This is also a huge drawback, when performing raids.

All of the above can be changed if a software product that can be installed on a tablet would be developed; the developed program would allow personnel, performing the raids, to show first consumers who have already stolen electricity, have arrears in payment for electricity

* Corresponding author: maksimka-borodin@yandex.ru 
consumed, made non-contractual consumption, carry out a process of technological connection or have non-meter accounting at the inspected site (feeder, settlement). In this case, the personnel, performing the raid, in the first place, would go to them with checks. If there are nonmeter consumers on the feeder, it is imperative to establish devices that control consumption. While personnel are carrying out raids, metering devices that control consumption can measure power consumption of non-meter consumers. If employees have identified theft from the above mentioned consumers, then they enter the necessary data into the program, which subsequently generates the necessary acts, certificates, etc. in real time and sends them for printing.

\section{Results and Discussion}

To implement the above mentioned idea, a software product algorithm has been developed. It provides for the identification of consumers who have already committed the electricity theft, have arrears in payment for consumed electricity, made non-contractual consumption, carry out the process of technological connection or have non-meter accounting. It also provides for the formation of the necessary acts, certificates, etc.in real time. The algorithm of the software product is shown in Figure 1.

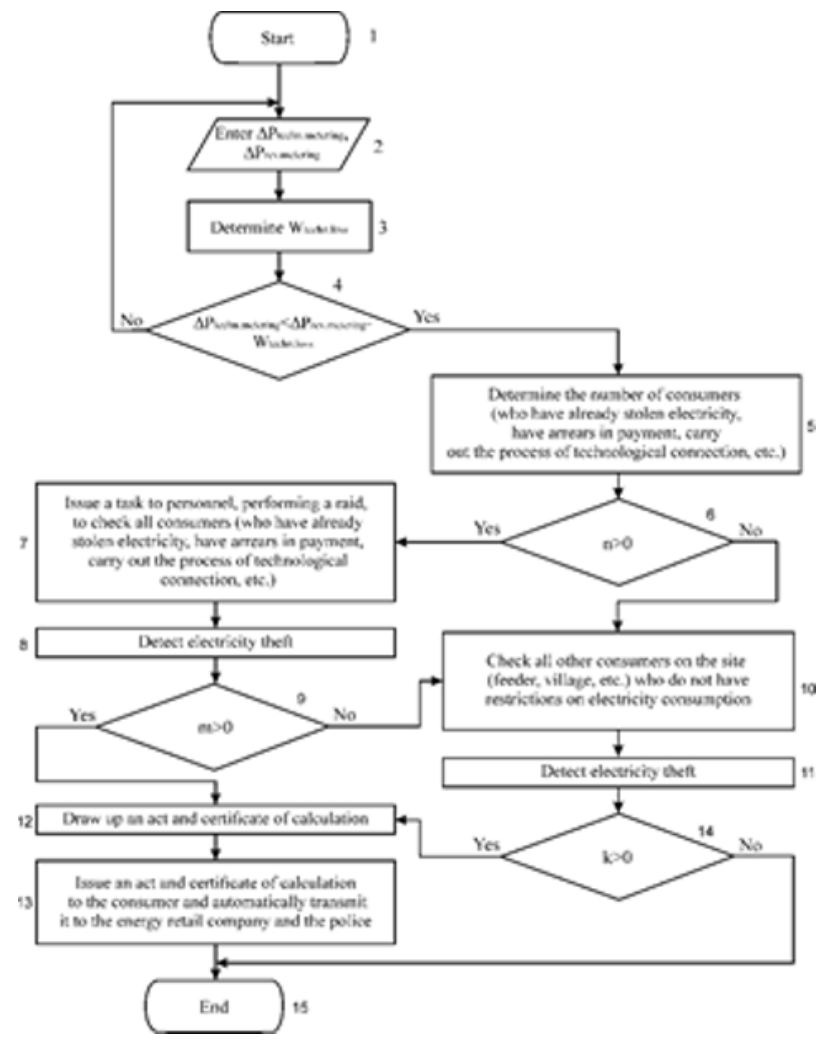

Fig. 1. The algorithm of the software product for determination the site of non-metered and non-contractual electricity consumption.

In the diagram: $\mathrm{T} 1$ - power transformer of the main poLet's consider the operation of the presented algorithm in cases where personnel are going to perform a raid to detect the electricity theft in a certain area (feeder, village).In this case, the beginning of the algorithm involves entering data on the amount of electricity passed through the site, the feeder, in the village $\left(\Delta \mathrm{P}_{\text {techn. metering }}\right)$ and the total amount of electricity $\left(\Delta \mathrm{P}_{\text {revenue metering }}\right)$ received by consumers. The indicated data can be selected for every hour, day, month or year. Unit 3 determines commercial losses of electricity $(\Delta \mathrm{W})$ and technological losses of electricity ( $\left.\mathrm{W}_{\text {techn. loss }}\right)$. Unit 4 compares the commercial losses of electricity in the area (feeder, village) with the planned indicators. When the values of commercial losses of electricity deviate from the norm, unit 4 sends a signal to unit 5, which determines the number of consumers who have already stolen electricity, have arrears in payment for consumed electricity, made non-contractual consumption, carry out the process of technological connection or have nonmeter accounting. If such consumers are detected, unit 6 sends a signal to unit 7 , which is responsible for issuing tasks to the personnel performing the raid to conduct the inspection. Unit 7 sends a signal to unit 8 , which is responsible for detectingelectricity theft.If the electricity theft was detected during a raid by consumers who have already stolen electricity, have arrears in payment for consumed electricity, made non-contractual consumption, carry out the process of technological connection or have non-meter accounting, then unit 9 determines the number of detected cases of electricity theft. After that, from unit 9, the signal goes to unit 12, which is responsible for drawing up the act and the certificate of calculation. Then the signal goes to unit 13, which is responsible for issuing the act and the certificate of calculation to the consumer on the spot and automatically transmits all the drawn up and filled in documents to the energy retail company and the police. If there are no consumers at the site (feeder, village) who have already stolen electricity, have arrears in payment for consumed electricity, made non-contractual consumption, carry out the process of technological connection or have non-meter accounting and new cases of electricity theft of the above mentioned consumers have not been revealed, a signal from units 6 and 9 goes to unit 10 , which is responsible for checking all other consumers available on the site (feeder, village). Next, the signal is transmitted to unit 11 , which is responsible for identifying new electricity thefts. If such a theft is detected, then the signal of unit 11 goes to unit 14, which determines the number of new cases of electricity thefts by "new consumers". If the electricity theft by consumers ("new consumers") was detected during the raid, then from unit 14 the signal goes to unit 12, which is responsible for drawing up the act and the certificate of calculation. Then the signal goes to unit 13, which is responsible for issuing the act and the certificate of calculation to the consumer on the spot and automatically transmits all the drawn up and filled in documents to the energy retail company and the police. In that case, if during the raid new cases of electricity theft were not detected, the signal from unit 14 is sent to unit 15.

The number of consumers who have already stolen electricity, have arrears in payment for consumed electricity, made non-contractual consumption, carry out 
the process of technological connection or have nonmeter accounting, is indicated by the variable $n$, while the number of new detected cases of electricity theft by the above mentioned consumers is indicated by the variable $\mathrm{m}$. The number of new cases of electricity theft by consumers not specified above is indicated by the variable $\mathrm{k}$.

To implement the software product in electric grid companies, it will need to be integrated with the SAP program. This integration will make it possible to obtain initial data on the amount of electricity consumed by consumers on the site (feeder, village), on consumers who have already stolen electricity, have arrears in payment for consumed electricity, made non-contractual consumption, carry out the process of technological connection or have non-meter accounting, etc.. If necessary, the program can show existing regulations aimed at conducting checks and raids to identify the electricity theft.

The increase in spot raids to detect electricity thefts will allow the electric grid companies to increase the territoriality of inspections. At the same time, the implementation of the software product in electric grid companies will significantly reduce the time for performing raids to detect electricity thefts.

\section{Conclusions}

Reducing the number of electricity thefts in electric grid companies is an urgent task. To reduce non-metered and non-contractual energy consumption, an algorithm that can be implemented as a software product has been developed. The presented software product allows, based on the registration of consumers who have already stolen electricity, have arrears in payment for consumed electricity, made non-contractual consumption, carry out the process of technological connection or have nonmeter accounting, send to themthe personnel,performing a raid, to identify electricity theft. It also makes possiblein real time to generate the necessary acts, certificates, etc., that allows personnel to reduce the time to fill out paper versions of documents.

The software product allows to increase the efficiency of raids, performed by electric grid companies, by reducing the time of inspections. In turn, the implementation of the program will allow electric grid companies to significantly reduce electricity losses by increasing the territoriality of raids.

\section{References}

[1] A.S. Semenov, Lower Economic Losses in Electric Networks, Applied Sciences and technologies in the United States and Europe: common challenges and scientific findings Proceedings of the 3th International scientific conference, ed. Ludwig Siebenberg, 139-141 (2013)

[2] F. Jamil, On the Electricity Shortage, Price and Electricity Theft Nexus, Energy Policy 54, 267272 (2013)
[3] A. Vinogradov, V. Bolshev, A. Vinogradova, T. Kudinova, M.Borodin, A. Selesneva, N. Sorokin, A System for Monitoring the Number and Duration of Power Outages and Power Quality in $0.38 \mathrm{kV}$ Electrical Networks, In: Vasant P., Zelinka I., Weber GW. (eds) Intelligent Computing \& Optimization, ICO 2018, Advances in Intelligent Systems and Computing 866, 1-10 (2019)

[4] S.M. Astakhov, R.P. Belikov, State and Ways to Improve the Performance of Distribution Networks in the Agro-industrial Complex, Bulletin of OrelSAU 29, 2, 106-108 (2011)

[5] M.V. Borodin, N.S. Uryupin, Justification of Energy-efficient Cross-section of Power Lines with Voltage Deviations of $\pm 5 \%, \pm 10 \%$, Bulletin of Nizhny Novgorod Institute of Engineering and Economics 2, 81, 20-29 (2018)

[6] M.V. Borodin, Analysis of Electric Power Losses in Electric Networks of Orlovsky Distribution Zone of Orelenergo branch of IDGC of Center, PJSC, Agrotechnics and Power Supply 4, 17, 46-53 (2017)

[7] A.I. Psarev, Analysis of Electric Power Losses in Electric Networks of the Branch of IDGC of Center - Orelenergo PJSC, Orlovsky Distribution Zone, Innovative Development of the University Library: Management and Marketing, Proceedings of the II Scientific and Practical Conference, 65-68 (2018)

[8] A.E. Semenov, Analysis of Electric Power Losses in Electric Networks of the Branch of IDGC of Center - Orelenergo, PJSC Livensky Distribution Zone, Innovative Development of the University Library: Management and Marketing, Proceedings of the II Scientific and Practical Conference, 68-71 (2018)

[9] D.V. Lukovnikov, Unaccounted-forand nonmetered power consumption, Proceedings of Bratsk State University. Series: Natural and Engineering Science 1, 43-47 (2017)

[10] M.V. Borodin, Yu.A. Volchenkov, A.V. Vinogradov, Development of Measures to Reduce Electricity Losses in the Branch of IDGC of Center - Orelenergo, Bulletin of DonAgrarian Science 4, 32, 27-34 (2015)

[11] M.V. Astiazara, D.A.C. Barone, Application of an Artificial Immune System to Predict Electrical Energy Fraud and Theft, ICEIS 2012 - Proceedings of the 14th International Conference on Enterprise Information Systems, 265-271 (2012)

[12] R.R. Shaikhutdinov, E.I. Gracheva, The Use of Modern Electrical Equipment to Reduce Electrical Energy Losses in Distribution Networks, Science and Education 3, 47, 29-31 (2019)

[13] M.V. Borodin, R.P. Belikov, N.V. Makhiyanova, Improving Power quality Through the Calculation of Voltage Losses, Bulletin of Don Agrarian Science 3, 47, 35-40 (2019)

[14] S.V. Krivonogov, Analysis of Electricity Theft in the Domestic Sector, Bulletin of Nizhny Novgorod 
Institute of Engineering and Economics 10, 41, 8288 (2014).

[15] O.A. Chausovsky, Modern Methods ofElectricity Theft and the Fight Against Them, Industrial Energy 1, 54-56 (2016)

[16] N.S. Sorokin, Improving the OperationEfficiency of Electrical Networks with Voltage of 6-35 kV by Monitoring the Parameters of the Electrical Network, National University of Life and Environmental Sciences of Ukraine, Series: Technics and Energy of the Agro-industrial Complex, 209-2, 92-95 (2015)

[17] K. Yevgeniy, Problems in Reimbursing Actual Damage in Cases of electricity theft, Ecology, Environment and Conservation 21, AS59-AS62 (2015)

[18] D.D. Micu, I.V. Ivshin, E.I. Gracheva, O.V. Naumov, A.N. Gorlov, Influence of Resistance of Contact Units of Switching Devices on the Electric Power Losses in Shop Networks of Low Voltage, E3S Web of Conferences 2019, 02013 (2019)

[19] A.V. Vinogradov, A.V. Vinogradova, V.E. Bolshev, M.O. Ward, N.V. Makhiyanova, L.V. Dolomaniuk, Justification for Creating a Mobile Complex to Assess Electric Energy Loss in Power Transformers During the Operation Process, E3S Web of Conferences 2019, 02009 (2019)

[20] E.I. Gracheva, O.V. Naumov, Estimation of Power Losses in Electric Devices of the Electrotechnical Complex, 2019 International Conference on Industrial Engineering, Applications and Manufacturing, ICIEAM 2019, 8742923 (2019) 